Check for updates

Cite this: Chem. Sci., 2018, 9, 5223

Received 3rd March 2018 Accepted 15th May 2018

DOI: $10.1039 / \mathrm{c} 8 \mathrm{sc} 01025 \mathrm{k}$

rsc.li/chemical-science

\title{
Dehydrogenative coupling of 4-substituted pyridines mediated by a zirconium(II) synthon: reaction pathways and dead ends $\uparrow$
}

\begin{abstract}
Lukas S. Merz, ${ }^{a}$ Hubert Wadepohl, ${ }^{a}$ Eric Clot $^{\star b}$ and Lutz H. Gade (D) *a
The mechanism of the reductive homocoupling of pyridine derivatives mediated by the $\mathrm{Zr}^{\prime \prime}$ synthon [(PNP) $\mathrm{Zr}\left(\eta^{6}\right.$ toluene) Cl] (1) has been investigated. Selective transformation into three different types of product complexes has been observed, depending on the $\mathrm{N}$-heterocyclic substrate employed: the bipyridyl complexes 3-R $(\mathrm{R}=\mathrm{Me}$, Et, $\left.{ }^{t} \mathrm{Bu}, \mathrm{Bn}, \mathrm{Ph}, \mathrm{CHCHPh}\right)$, which are the homocoupling products, the $\eta^{2}$-((4-dimethylamino)pyridyl) complex 4 as well as the bis(isoquinolinyl) complex 5. By deuterium labelling experiments the participation of the ligand backbone in the pyridine coupling reaction via potential cyclometallation steps was ruled out. Based on DFT modelling of the possible reaction sequences a reaction mechanism for the coupling sequence could be identified. The latter is initiated by a reductive syn $\mathrm{C}-\mathrm{C}$ coupling rather than based on an initial $\mathrm{C}-\mathrm{H}$ activation of the pyridine substrate.
\end{abstract}

\section{Introduction}

Early transition metal complexes are known to induce characteristic types of $\mathrm{C}-\mathrm{H}$ activations ${ }^{\mathbf{1 - 1 5}}$ which complement the analogous reactivity patterns established for their d-electron rich late transition metal counterparts. ${ }^{16-25}$ Cyclometallations may be viewed as particularly favourable variations of this type of reactivity ${ }^{26-34}$ and in their simplest form give rise to threemembered metallacycles. In this context group 4 metal compounds were found to activate pyridine to give pyridyl complexes incorporating $\eta^{2}$-N,C-metallazirine moieties. ${ }^{35-45}$ Generally, the formation of these $\eta^{2}$-pyridyl ligands may occur in two ways: either an alkyl substituent in $\mathrm{M}^{\mathrm{IV}}$ alkyl complexes abstracts a proton from a coordinated pyridine molecule to generate the metallacycle ${ }^{33,38-43}$ or an $\mathrm{M}^{\mathrm{II}}$ species, commonly generated in situ from the corresponding $\mathrm{M}^{\mathrm{IV}}$ complexes, activates the pyridine molecule through oxidative addition with concomitant formation of an additional hydrido ligand. ${ }^{35,36,46}$ The former activation pattern was most recently utilized by Mindiola, Baik and coworkers in a detailed study which demonstrated that the transitory generation of a titanaazirine

${ }^{a}$ Anorganisch Chemisches Institut, Universität Heidelberg, Im Neuenheimer Feld 270, 69120 Heidelberg, Germany. E-mail: lutz.gade@uni-heidelberg.de

${ }^{b}$ Institut Charles Gerhardt Montpellier, UMR 5253 CNRS-UM-ENSCM, Université de Montpellier, Place Eugène Bataillon, Bât 15, cc1501, 34095 Montpellier Cedex 5, France. E-mail: eric.clot@umontpellier.fr

$\dagger$ Electronic supplementary information (ESI) available: Includes experimental details and characterization data of all new compounds, synthetic protocols, spectral data, X-ray crystallographic information (CIF), and xyz-files of the DFT-optimized geometries. CCDC 1826625-1826628. For ESI and crystallographic data in CIF or other electronic format see DOI: $10.1039 / \mathrm{c} 8 \mathrm{sc} 01025 \mathrm{k}$ species from the benzopyridines, quinoline, and isoquinoline could result in the $\mathrm{C}-\mathrm{C}$ coupling (as well as ring opening) of two substrate molecules. ${ }^{47}$

It is notable that despite its broad application as a ligand in coordination chemistry, ${ }^{48-51}$ the generation of $2,2^{\prime}$-bipyridine directly from pyridine is still in its infancy especially since transition metal catalysed cross-coupling reactions generally require 2-halopyridines and 2-metallated pyridines. ${ }^{52}$ Without prior functionalization of the pyridine cycle, the direct synthesis of $2,2^{\prime}$ bipyridines is hitherto almost entirely restricted to the application of heterogeneous catalysts such as RANEY® nickel and Pd/ C. ${ }^{53-56}$ To our knowledge, only three homogeneous catalytic systems, using di- or trinuclear $\mathrm{Ru}$ - or $\mathrm{Ru} / \mathrm{Co}$-complexes, ${ }^{57-59}$ have been reported that are capable of catalysing the homocoupling of pyridines. Furthermore, even examples for the stoichiometric transformation of pyridine to 2,2'-bipyridine are rare and have only been described for a limited number of substrates (cf. Chart 1). ${ }^{60-63}$ The reaction pathways involved remain incompletely understood.

Recently, we reported the synthesis of the ${ }^{\mathrm{Cbz}}(\mathrm{PNP}) \operatorname{ZrCl}\left(\eta^{6}\right.$ arene) complex 1, in which the $\eta^{6}$-toluene ligand displays

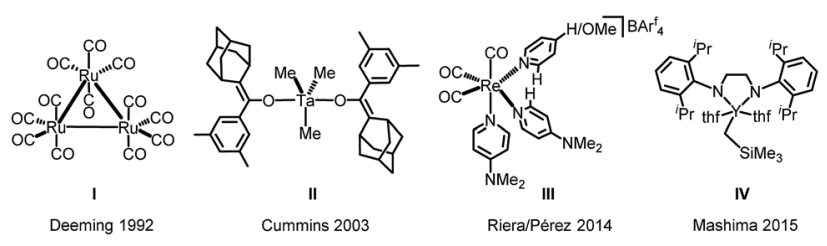

Chart 1 Selection of transition metal complexes mediating the stoichiometric reductive coupling of pyridine to 2,2'-bipyridine (II: reaction under $\mathrm{H}_{2}$ atmosphere; III: $\mathrm{KN}\left(\mathrm{SiMe}_{3}\right)_{2}$ and $\mathrm{AgOTf}$ are needed additionally). 


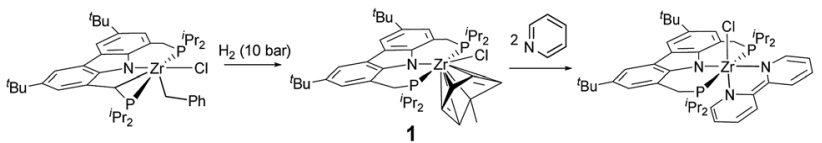

Scheme 1 Hydrogenolytic formation of $\mathrm{Zr}^{\prime \prime}$ synthon 1 from a cyclometallated benzyl complex and its reaction with two molar equivalents of pyridine.

a puckered arrangement of the arene ring similar to other early TM arene complexes. ${ }^{64-68}$ This indicates a significant arene-1,4diido character of the tolyl ring, and the zirconium atom in this complex is therefore to be assigned to the oxidation state +4 .

However, complex 1 can be regarded as a $\mathrm{Zr}^{\mathrm{II}}$ synthon, since the displacement of a neutral toluene molecule would provide access to a transient $\mathrm{Zr}^{\mathrm{II}}$ species. This could be demonstrated inter alia by the reductive coupling of pyridine to form a dianionic bipyridyl ligand coordinated to the zirconium centre (Scheme 1) ${ }^{69}$ The latter raised the question about the scope of this transformation, on the one hand, and the reaction mechanism which leads to this dehydrogenative $\mathrm{C}-\mathrm{C}$ coupling of two $\mathrm{N}$-heterocycles. The latter was deemed to involve a complex sequence of bond scission and formation steps within the coordination sphere of the metal atom. In this work new light will be shed on this type of reaction highlighting the specific preconditions for such a transformation as well as the unproductive dead ends of the underlying network of reaction steps.

\section{Discussion}

To obtain the first experimental mechanistic clues for the zirconium mediated reductive coupling of pyridine, we probed the substrate scope for this transformation using the isolated $\eta^{6}$-arene complex 1 . $^{69}$

In the first assay, monitored in situ by ${ }^{31} \mathrm{P}$ NMR spectroscopy, four methyl substituted pyridines were tested (Table 1) and it

Table 1 Dehydrogenative coupling of differently substituted pyridines mediated by $1^{a}$



\begin{tabular}{llrll} 
Entry & Substrate & $\mathrm{T}^{c}\left[{ }^{\circ} \mathrm{C}\right]$ & Time $[\mathrm{h}]$ & Ratio A:B ${ }^{d e}$ \\
\hline 1 & $\mathrm{R}^{2}=\mathrm{Me}, \mathrm{R}^{1,3,4}=\mathrm{H}$ & 60 & 16 & $-^{b}$ \\
2 & $\mathrm{R}^{2,4}=\mathrm{Me}, \mathrm{R}^{1,3}=\mathrm{H}$ & 80 & 48 & $-^{b}$ \\
3 & $\mathrm{R}^{1}=\mathrm{Me}, \mathrm{R}^{2-4}=\mathrm{H}$ & 100 & 16 & $66: 34$ \\
4 & $\mathrm{R}^{3}=\mathrm{Me}, \mathrm{R}^{1,2,4}=\mathrm{H}$ & 60 & 16 & $80: 20$
\end{tabular}

${ }^{a}$ The reactions were carried out in NMR tubes fitted with J. Young valves with $20 \mathrm{mg}$ ( $26 \mu \mathrm{mol}, 1.0$ equiv.) of 1 with 2.0 equivalents of the corresponding pyridine. ${ }^{b}$ Unselective conversion to unidentified products was observed. ${ }^{c}$ Temperature was gradually increased from RT to either 60,80 or $100{ }^{\circ} \mathrm{C}$ in case no reaction occurred. ${ }^{d} \mathrm{~A}=$ main product; $\mathrm{B}=$ unidentified by-product(s); judged by ${ }^{31} \mathrm{P}$ spectroscopy. ${ }^{e}$ Starting complex 1 was fully consumed in the stated reaction time; judged by ${ }^{31} \mathrm{P}$ NMR spectroscopy. was found that the previously observed reductive coupling reaction strongly depended on the substitution pattern. For pyridines methylated in the meta-position, unselective conversion into a variety of unidentifiable products was observed (Table 1, entries 1-2), 2-picoline underwent cyclometallation at the metal but no subsequent $\mathrm{C}-\mathrm{C}$ coupling occurred (Table 1, entry 3 and Scheme 2, left) whereas 4-picoline was transformed to the expected dimethylated bipyridine (Table 1 , entry 4 and Scheme 2, right).

For the 2-picoline substrate the observation of two doublet resonances in the ${ }^{31} \mathrm{P}\left\{{ }^{1} \mathrm{H}\right\}$ NMR spectrum $\left(\delta\left({ }^{31} \mathrm{P}\right)[\mathrm{ppm}]=18.2\right.$ $\left.\left(\mathrm{d}, J_{\mathrm{PP}}=25.4 \mathrm{~Hz}\right),-1.2\left(\mathrm{~d}, J_{\mathrm{PP}}=25.4 \mathrm{~Hz}\right)\right)$ indicated the cyclometallation of one of the methylene bridges of the ${ }^{\mathrm{Cbz}} \mathrm{PNP}$ pincer ligand..$^{70}$ The result of a single crystal X-ray structure analysis confirmed the identity of complex 2 as an $\eta^{2}$-pyridyl species (see ESI $\dagger$ ). The results obtained for 2-, 3- and 4-substituted methyl pyridines indicated that the reductive C-C coupling reaction mediated by $\eta^{6}$-arene complex 1 proceeded exclusively with 4 -substituted pyridines.

The formation of the dianionic bipyridine ligand in the reaction of 1 with 4-picoline was accompanied by a change of colour from brown to deep purple and conversion to 3-Me was completed after $16 \mathrm{~h}$ at $60^{\circ} \mathrm{C}(c f$. Scheme 2 and Table 1 , entry 4$)$. The reaction product was identified by ${ }^{31} \mathrm{P}\left\{{ }^{1} \mathrm{H}\right\}$ NMR spectroscopy $\left(\delta\left({ }^{31} \mathrm{P}\left\{{ }^{1} \mathrm{H}\right\}\right)=23.4 \mathrm{ppm}(\mathrm{bs})\right)$ as well as a characteristic set of signals in the ${ }^{1} \mathrm{H}$ NMR spectrum. In the case of 3-Me, this set consists of three different doublet and two singlet signals spread over a range of $5 \mathrm{ppm}$ representing the six protons of the bipyridyl ligand $\left[\delta\left({ }^{1} \mathrm{H}\right)=9.18\left(\mathrm{~d}, J_{\mathrm{HH}}=7.1 \mathrm{~Hz}, 1 \mathrm{H}\right) ; \delta\left({ }^{1} \mathrm{H}\right)=7.31\right.$ $(\mathrm{bs}, 1 \mathrm{H}) ; \delta\left({ }^{1} \mathrm{H}\right)=6.33(\mathrm{~s}, 1 \mathrm{H}) ; 6.31(\mathrm{~s}, 1 \mathrm{H}) ; \delta\left({ }^{1} \mathrm{H}\right)=4.87\left(\mathrm{~d}, J_{\mathrm{HH}}=\right.$ $7.0 \mathrm{~Hz}, 1 \mathrm{H}) ; 4.29$ (d, $\left.\left.J_{\mathrm{HH}}=7.0 \mathrm{~Hz}, 1 \mathrm{H}\right) \mathrm{ppm}\right]$.

To further investigate the scope of the coupling reaction, a series of 4-substituted pyridines was reacted with complex 1 ( $c f$. Table 2). A general reactivity trend emerged in this study: pyridine substrates with reduced electron density in the aromatic ring did not undergo the reductive coupling reaction $(c f$. Table 2 , entry $1+2)$ while the reaction with an electron-rich pyridine resulted in the formation of the coupled heterocycle along with significant amounts of side products, precluding the isolation of the respective bipyridyl complex ( $c f$. Table 2, entry 10). However, substrates with similar electronic properties to the unsubstituted pyridine were readily transformed to the desired bipyridyl ligand. These included a variety of alkyl as well as $\mathrm{sp}^{2}$ substituted pyridines (Table 2, entries 3-9).

As expected, all bipyridyl complexes possess very similar properties: they are deeply coloured in the solid state and in solution, highly sensitive towards oxygen and moisture, and all display a characteristic set of proton resonances for the newly

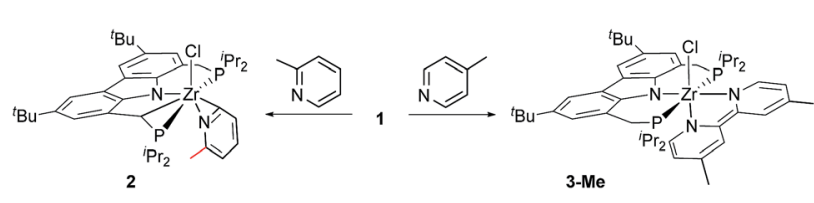

Scheme 2 Reactivity of arene complex 1 with 2-picoline in contrast to the reactivity with 4 -picoline (product 2 could not be purely isolated; observed via ${ }^{1} \mathrm{H}$ NMR and X-ray analysis). 
Table 2 Expanding the substrate scope for the dehydrogenative coupling of 4 -substituted pyridines mediated by complex 1
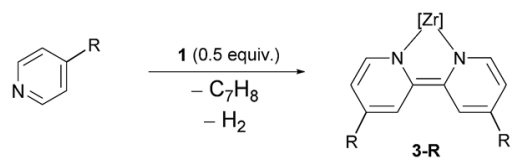

\begin{tabular}{lllll}
\hline Entry & Substrate & $\mathrm{T}\left[{ }^{\circ} \mathrm{C}\right]^{\mathrm{c}}$ & Time $[\mathrm{h}]$ & $\begin{array}{l}\text { Isolated yield } \\
{[\%]}\end{array}$ \\
\hline 1 & $\mathrm{R}=\mathrm{CF}_{3}$ & 80 & 24 & - $^{a}$ \\
2 & $\mathrm{R}=\mathrm{CN}$ & 50 & 24 & ${ }^{a}$ \\
3 & $\mathrm{Pyridine-d_{5 }}$ & 50 & 19 & 21 \\
4 & $\mathrm{R}=\mathrm{Me}$ & 60 & 16 & 18 \\
5 & $\mathrm{R}=\mathrm{Et}$ & 50 & 19 & 25 \\
6 & $\mathrm{R}={ }^{t} \mathrm{Bu}$ & 50 & 19 & 34 \\
7 & $\mathrm{R}=\mathrm{CH}{ }_{2} \mathrm{Ph}$ & 50 & 19 & 42 \\
8 & $\mathrm{R}=\mathrm{Ph}$ & 60 & 19 & 44 \\
9 & $\mathrm{R}=\mathrm{CHCHPh}$ & 50 & 19 & $-{ }^{a}$ \\
10 & $\mathrm{R}=\mathrm{OMe}$ & 50 & 19 & 42 \\
11 & $\mathrm{R}=\mathrm{NMe}_{2}$ & 25 & 20 &
\end{tabular}

${ }^{a}$ Unselective conversion to unidentified products was observed.

formed bipyridine ligand between 9.2 and $4.5 \mathrm{ppm}$ (in addition to the resonances of their respective substituents). The extreme solubility of all complexes in hydrocarbons, including $n$-pentane and $n$-hexane, led to significant discrepancies between the observed degree of conversion and the actual isolated yields in the purification based on washing or recrystallization.

For ${ }^{3}{ }^{t} \mathbf{B u}$, the crystal structure was determined from single crystals grown by cooling saturated $n$-pentane solutions to $-40{ }^{\circ} \mathrm{C}$ (cf. Fig. 1). As expected, the molecular structure displays octahedral coordination geometry with the ${ }^{\mathrm{Cbz}}(\mathrm{PNP})$ ligand in a meridional coordination mode while the other three coordination sites are occupied by the chlorido and the bipyridyl ligand. The molecule is approximately $C_{\mathrm{s}}$ symmetric along the equatorial plane of the octahedron, which is in agreement with the symmetry derived from the NMR signal patterns in solution.

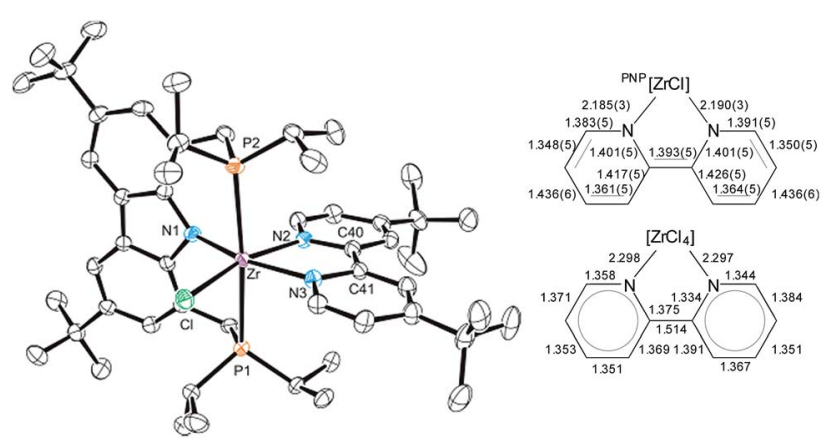

Fig. 1 Left: molecular structure of $3-{ }^{t} \mathrm{Bu}$ (hydrogen atoms were omitted for clarity, ellipsoids set at $50 \%$ probability). Selected bond lengths $[\AA \AA]$ and angles $\left[{ }^{\circ}\right]$ for $3-{ }^{t} \mathrm{Bu}: \mathrm{Zr}-\mathrm{Cl}$ 2.4931(9), $\mathrm{Zr}-\mathrm{P} 12.7490(10)$, $\mathrm{Zr}-\mathrm{P} 2$ 2.7436(10), Zr-N1 2.243(3), Zr-N2 2.190(3), Zr-N3 2.185(3), Cl$\mathrm{Zr}-\mathrm{P} 1$ 87.16(3), Cl-Zr-P2 91.52(3), P2-Zr-P1 175.39(3), N1-Zr-Cl 105.42(8), N1-Zr-N2 88.79(11), N2-Zr-N3 71.09(11), N3-Zr-Cl 94.48(8), N2-Zr-P1 87.99(8), N2-Zr-P2 94.38(8). Right: comparison between bond lengths: bipy ${ }^{2-}$ of $3-{ }^{t} \mathrm{Bu}$ to bipy ${ }^{0}{ }^{71}$
The dianionic character of the bipyridyl ligand becomes apparent upon comparison of its $\mathrm{C}-\mathrm{C}$ and $\mathrm{Zr}-\mathrm{N}$ bond lengths with those of a zirconium bipy ${ }^{0}$ complex reported in the literature ( $c$ f. Fig. 1). ${ }^{71}$ In the molecular structure of $3-{ }^{t} \mathrm{Bu}$, contracted $\mathrm{Zr}-\mathrm{N}$ bond lengths (Zr-N2 2.190(3); Zr-N3 2.185(3)) as well as alternatingly shortened $\mathrm{C}-\mathrm{C}$ bond lengths within and between the two pyridine rings were found, suggesting the (partial) loss of aromatic character in the bipyridyl ligand and the localization of the double bonds. The presence of a bipy ${ }^{2-}$ ligand is further corroborated by two broad absorption bands in the UV/ Vis spectrum that can be attributed to the intraligand $\pi-\pi^{*}$ transitions of the bipy ${ }^{2-}$ ligands. ${ }^{72-74}$

As mentioned above, an increase of electron density in the pyridine substrate tended to give rise to an inseparable product mixture ( $c f$. Table 2, entry 10). However, further increase in the electron donating character of the substituent in the 4-position (in this case an $N, N$-dimethylamine substituent in 4 -(dimethylamino)pyridine (DMAP)) led to the selective conversion into cyclometallated pyridyl complex 4 ( $c f$. Table 2, entry 11 and Scheme 3). As for the analogous complex 2 , the ${ }^{1} \mathrm{H},{ }^{13} \mathrm{C}$ and ${ }^{31} \mathrm{P}$ NMR spectra of 4 indicated a C-H activated ligand backbone of the PNP pincer.

The ${ }^{1} \mathrm{H}$ NMR spectrum of the isolated product, in particular, illustrated the activation of the ligand backbone. Due to the loss of one proton in the $\mathrm{CH}_{2}$-linkers, both linker units give rise to a characteristic signal pattern: three separate signals with the relative intensities of one proton each $\left(\delta\left({ }^{1} \mathrm{H}\right)[\mathrm{ppm}]=4.95(\mathrm{dd}\right.$, $\left.J_{\mathrm{HH}}=16.0 \mathrm{~Hz}, J_{\mathrm{HP}}=4.4 \mathrm{~Hz}\right), 3.60\left(\mathrm{dd}, J_{\mathrm{HH}}=14.9 \mathrm{~Hz}, J_{\mathrm{HP}}=14.9\right.$ $\mathrm{Hz}), 2.39(\mathrm{~m}))$.

To establish the structural details of $\mathbf{4}$, a single-crystal X-ray structure analysis was carried out (Fig. 2). It confirmed the presence of the cyclometallated ligand backbone of the ${ }^{\mathrm{Cbz}}(\mathrm{PNP})$ pincer ligand causing a deformation of the natural meridional coordination mode drawing the coordinating phosphines towards each other. As in compound 2, the pyridine substrate had undergone ortho $\mathrm{C}-\mathrm{H}$ activation to form an $\eta^{2}$-pyridyl unit; however, in the case of $\mathbf{4}$ an additional substrate molecule is coordinated to the metal atom. As opposed to the solid-state structure of ${ }^{3-}{ }^{t} \mathbf{B u}$ (Fig. 1) the coordination mode for the ${ }^{\mathrm{Cb}} \mathrm{PNP}$ ligand in $\mathbf{4}$ is better described as distorted facial than as meridional with the remaining three coordination sites being inhabited by the $\eta^{2}$-pyridyl moiety, and the chlorido and the DMAP ligand.

Given the formation of the $\eta^{2}$-pyridyl complexes $\mathbf{2}$ and $\mathbf{4}$, there appeared to be a pronounced tendency of the ${ }^{\mathrm{Cbz}}$ (PNP) ligand in combination with early TM to undergo cyclometallation reactions. ${ }^{70}$ It therefore was conceivable that the activation of the ligand backbone played a part in the reaction


Scheme 3 Conversion of $\eta^{6}$-arene complex 1 with 4-(N,N-dimethylamino)pyridine to cyclometallated $\eta^{2}$-pyridyl complex ( $\left.L=D M A P\right)$. 




Fig. 2 Molecular structure of 4. Hydrogen atoms and one isopropyl group were omitted for clarity, ellipsoids set at 50\% probability. Selected bond lengths $[\AA ̊]$ and angles $\left[^{\circ}\right]$ for 4: $\mathrm{Zr}-\mathrm{Cl} 2.5597(7), \mathrm{Zr}-\mathrm{P} 1$ 2.7280(7), $\mathrm{Zr}-\mathrm{P} 2$ 2.8220(7), $\mathrm{Zr}-\mathrm{N} 1$ 2.260(2), $\mathrm{Zr}-\mathrm{N} 2$ 2.204(2), Zr-N4 2.395(2), Zr-C14 2.412(3), Zr-C36 2.226(3), Cl-Zr-P1 168.16(2), Cl$\mathrm{Zr}-\mathrm{P} 2$ 75.27(2), $\mathrm{P} 2-\mathrm{Zr}-\mathrm{P} 1$ 92.90(2), $\mathrm{N} 1-\mathrm{Zr}-\mathrm{Cl} 99.18(5), \mathrm{N} 1-\mathrm{Zr}-\mathrm{N} 2$ 162.55(8), N2-Zr-N4 86.42(7), N2-Zr-Cl 93.01(6), N2-Zr-P1 93.82(6), N2-Zr-P2 122.69(6).

pathway resulting in the reductive coupling of pyridines. In this context, an initial $\mathrm{C}-\mathrm{H}$ activation step forming an $\left(\eta^{2}\right.$-pyridyl) zirconium(Iv) hydride species appeared to be possible. ${ }^{36}$ Such a potential intermediate in turn could activate the ligand backbone to provide A through elimination of $\mathrm{H}_{2}$ ( $c f$. Chart 2). After the coordination of a second substrate molecule, $\mathrm{C}-\mathrm{C}$ coupling could take place forming complex $\mathbf{B}$ while the ${ }^{\mathrm{Cbz}}(\mathrm{PNP})$ ligand would be restored in the last step through an $\mathrm{H}$-atom transfer from the coupled bipyridyl ligand to generate complex C.

Such a reaction pathway would imply hydrogen atom exchange between the methylene hydrogen atoms in the PNP pincer and the pyridine substrate. Thus, in order to probe this specific consequence of such a mechanism the coupling reaction was repeated with pyridine- $\mathrm{d}_{5}$ in benzene- $\mathrm{d}_{6}$. This did not lead to deuterium incorporation into the ligand backbone (cf. Fig. 3) which allowed us to exclude such a cyclometallation step involving the PNP ligand backbone. It also implied that the isolated complexes $\mathbf{2}$ and $\mathbf{4}$ were the result of a competitive reaction pathway not leading to the formation of a bipy ${ }^{2-}$ complex but rather representing a dead end for this type of transformation.

In the course of the substrate screening a remarkable new reactivity pattern was observed. When isoquinoline was reacted with $\mathrm{Zr}^{\mathrm{II}}$ synthon 1, the isoquinoline indeed underwent a C-C

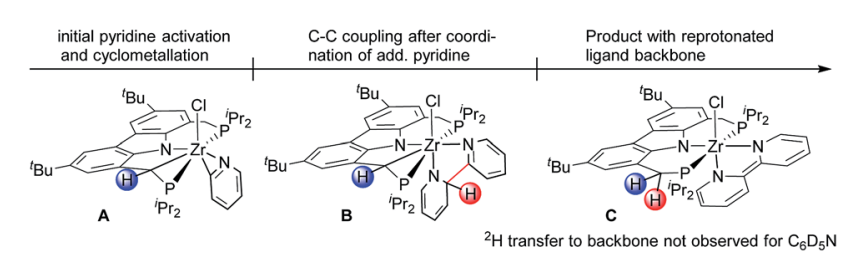

Chart 2 Illustration of essential intermediates envisioned for the reductive coupling of pyridine involving a cyclometallated ligand backbone.

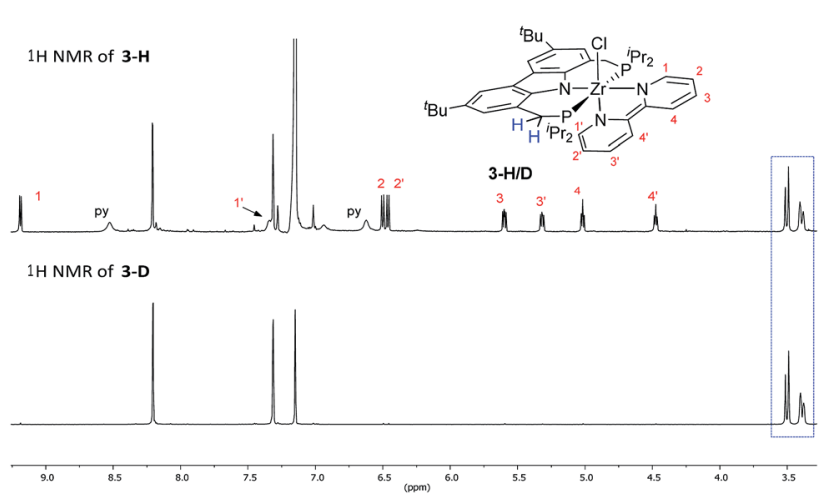

Fig. 3 Comparison of ${ }^{1} \mathrm{H}$ NMR $(600.13 \mathrm{MHz}, 298 \mathrm{~K})$ spectra of $3-\mathrm{H}$ with 3-D. The two doublet signals marked by the blue rectangle belong to the methylene bridges of the coordinated ${ }^{\mathrm{Cbz}}$ (PNP) ligand. Consequently, there is no indication of deuteration of these positions.

coupling reaction yielding bisisoquinoline complex 5. However, the NMR data of the product indicated that the coupling step occurred without the loss of the two hydrogen atoms at the bridge carbons ${ }^{75}$ as it was the case for several of the 4-substituted pyridine substrates (Scheme 4).

An X-ray diffraction study of 5 established the details of its molecular structure (Fig. 4). The molecular structure revealed a complex with distorted octahedral coordination geometry, in which a bisisoquinoline ligand occupies two coordination sites. The $\mathrm{C} 1-\mathrm{C}^{\prime}$ bond length of the bisisoquinoline ligand is consistent with a single bond between the separate isoquinoline moieties. Moreover, the solid-state structure confirmed that no formal elimination of dihydrogen had occurred and that the remaining hydrogen atoms at the bridge carbons are arranged in the anti-disposition. In combination with the twisted isoquinoline moieties, these hydrogen atoms break the $C_{\mathrm{s}}$ symmetry generally found in complexes lacking an activated ligand backbone. As a result, the ${ }^{1} \mathrm{H}$ and ${ }^{31} \mathrm{P}$ NMR spectra show the signal patterns corresponding to a $C_{1}$ symmetric complex.

\section{DFT modelling of the reductive coupling of 4-substituted pyridines}

As group 4 complexes are known to promote the $\mathrm{C}-\mathrm{H}$ activation of pyridines, the formation of an $\eta^{2}$-pyridyl complex was initially assumed as the logical $\mathrm{Zr}^{\mathrm{IV}}$ intermediate in the mechanism to form complexes 3-R. However, there are reports of a high propensity of $\mathrm{Zr}^{\mathrm{II}}$ species, such as the one generated from 1 on elimination of toluene, to facilitate $\mathrm{C}-\mathrm{C}$ coupling reactions. Exemplary work has been reported by Rosenthal and co-workers with utilization of zirconacenes. ${ }^{76-81}$ Due to this reactivity of low-

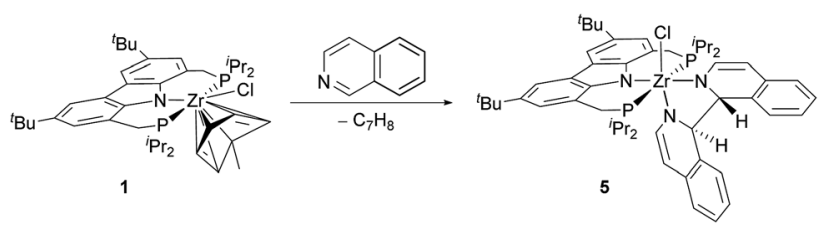

Scheme 4 Reaction of $\mathrm{Zr}^{\prime \prime}$ synthon 1 with isoquinoline. 


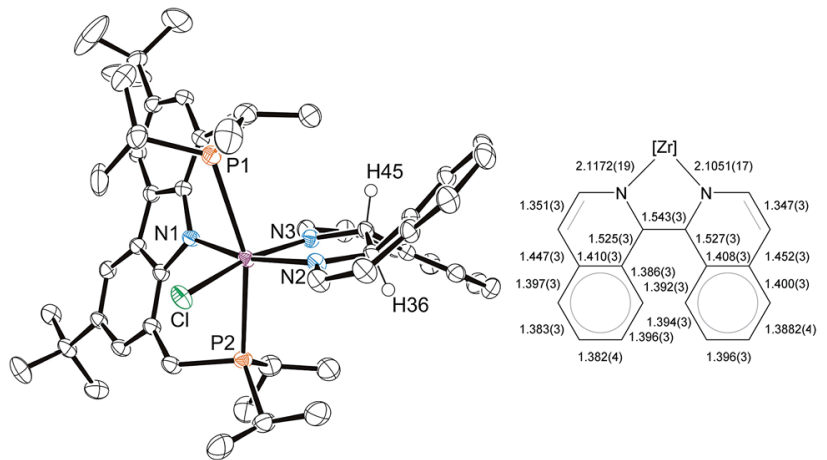

Fig. 4 Left: molecular structure of 5 (only one of the two independent molecules is shown; most hydrogen atoms were omitted for clarity, ellipsoids set at $50 \%$ probability). Selected bond lengths $[\AA]$ and angles $\left[{ }^{\circ}\right]$ for 5 (values in square brackets refer to the second independent molecule): $\mathrm{Zr}-\mathrm{Cl}$ 2.5130(5) [2.5062(5)], $\mathrm{Zr}-\mathrm{P} 1$ 2.7506(6) [2.7425(5)], $\mathrm{Zr}-\mathrm{P} 2$ 2.7262(5) [2.7234(5)], Zr-N1 2.2450(16) [2.2484(15)], Zr-N2 2.1051(16) [2.1122(16)], $\mathrm{Zr}-\mathrm{N} 3 \quad 2.1179(17)$ [2.1215(16)], $\mathrm{Cl}-\mathrm{Zr}-\mathrm{P} 1$ 85.940(19) [86.674(18)], Cl-Zr-P2 85.253(18) [84.928(18)], P2-Zr-P1 160.277(17) [157.902(17)], N1-Zr-Cl 103.34(4) [104.13(4)], N1-Zr-N2 162.90(7) [163.25(6)], N2- $\mathrm{Zr}-\mathrm{N} 3$ 75.02(6) [74.84(6)], N3- $\mathrm{Zr}-\mathrm{Cl}$ 166.50(5) [165.05(4)], N2-Zr-P1 96.26(5) [97.13(5)], N2-Zr-P2 101.77(5) [103.51(5)]. Right: illustration of $\mathrm{C}-\mathrm{C}$ bond lengths in the bis(isoquinoline) ligand of the depicted molecule. valent zirconium species and the occurrence of complex $\mathbf{5}$, the possibility of the $\mathrm{C}-\mathrm{C}$ coupling of the substrates prior to their $\mathrm{C}-\mathrm{H}$ activation could not be neglected as a viable reaction mechanism. Hence, two general reaction sequences were envisaged: (i) the initial $\mathrm{C}-\mathrm{H}$ activation of one pyridine molecule, as it has previously been proposed, ${ }^{61}$ and (ii) the C-C bond formation as the first reaction step. To distinguish between these sequences of events, DFT (PBE0) modelling for the two alternative reaction pathways was performed.$^{82}$ The calculated reaction energy profiles for the reductive $\mathrm{C}-\mathrm{C}$ coupling of pyridine are summarized in Fig. 5. Both pathways start with the extrusion of a neutral toluene molecule by pyridine to form the $\mathrm{Zr}^{\mathrm{II}}$ species 1-py in an almost thermoneutral transformation.

In the case of the $\mathrm{C}-\mathrm{H}$ activation pathway (Fig. 5, blue), isomerisation to a geometry, $\mathbf{C H}-\mathbf{1}$, with the $\mathrm{C}-\mathrm{H}$ bond at the 2position ready to be cleaved is exergonic $(\Delta G=$ $-6.1 \mathrm{kcal} \mathrm{mol}^{-1}$ ). The actual $\mathrm{C}-\mathrm{H}$ bond cleavage is effective through CH-1-TS with an activation barrier of $\Delta G^{\ddagger}=$ $11.8 \mathrm{kcal} \mathrm{mol}^{-1}$, leading to the $\eta^{2}$-N,C-pyridyl intermediate $\mathbf{C H}$ 2. After the endergonic coordination of an additional pyridine molecule to yield $\mathbf{C H}-\mathbf{3}$, the formation of the new $\mathrm{C}-\mathrm{C}$ bond between the two heterocycles is effective through $\mathbf{C H}-3-\mathbf{T S}$ with an activation barrier of $\Delta G^{\ddagger}=24.7 \mathrm{kcal} \mathrm{mol}{ }^{-1}$ from $\mathbf{C H}-3$. The

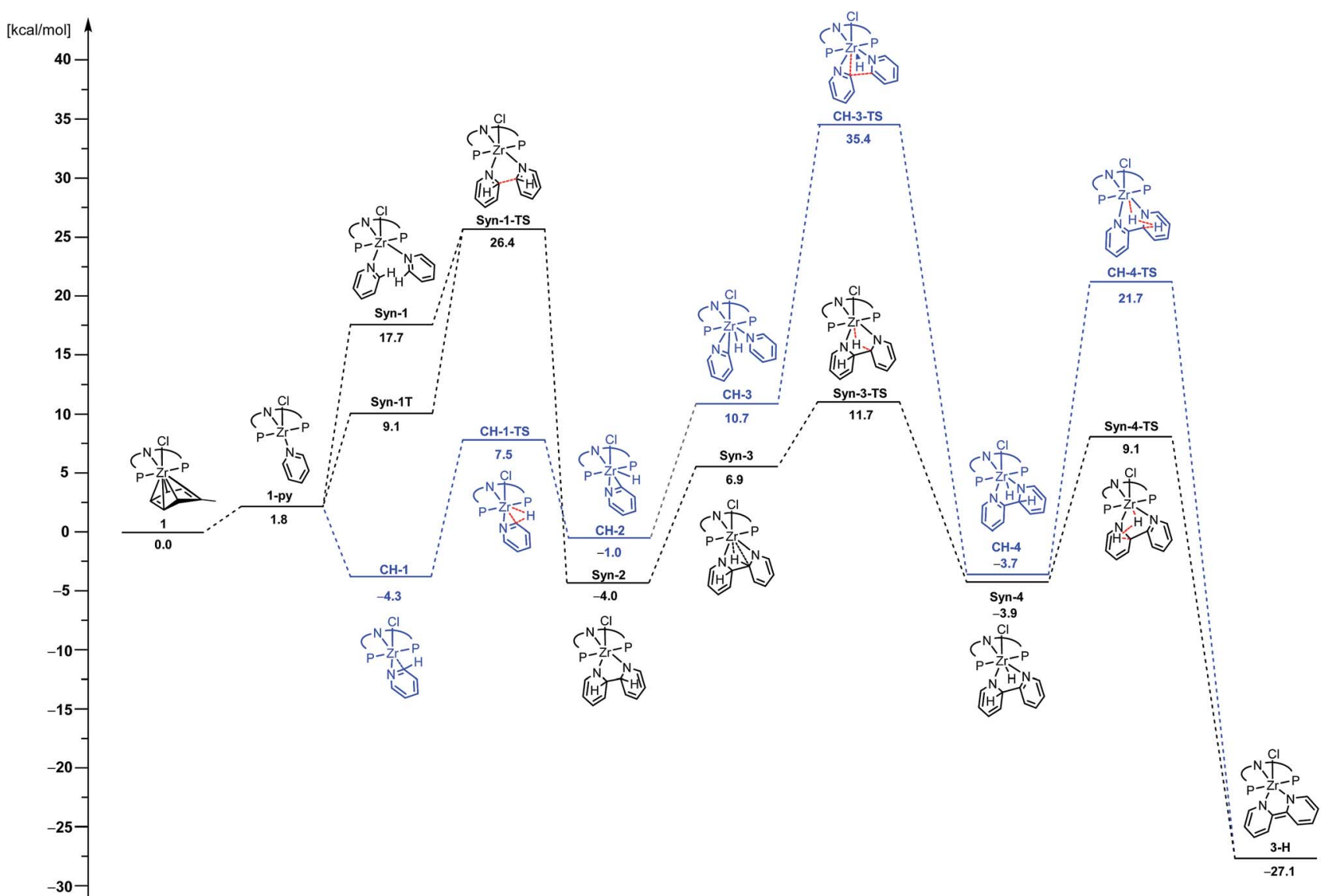

Fig. 5 Calculated free energies $\left(\mathrm{kcal} \mathrm{mol}^{-1}\right)$ of key intermediates and transition states of two envisaged reaction sequences at 1 bar and $60{ }^{\circ} \mathrm{C}$. Blue represents a pathway with an initial $\mathrm{C}-\mathrm{H}$ activation step, whereas black depicts a pathway with the $\mathrm{C}-\mathrm{C}$ coupling step of inactivated pyridine as the first transformation (all structures except Syn-1T have been computed as singlet species; all structures but 1-py, Syn-1 and $\mathrm{CH}-1$ are $\mathrm{Zr}^{\mathrm{IV}}$ species). 
resulting product of this $\mathrm{C}-\mathrm{C}$ coupling is barely less stable than the initial complex $\mathbf{C H}-\mathbf{1}\left(\Delta G=+0.6 \mathrm{kcal} \mathrm{mol}^{-1}\right)$. The final product of the transformation, $3-\mathbf{H}$, is obtained when $\mathrm{H}_{2}$ is formed through CH-4-TS with an activation barrier of $\Delta G^{\ddagger}=$ $25.4 \mathrm{kcal} \mathrm{mol}^{-1}$ from CH-4. Overall, the energy barrier to overcome is $\Delta G^{\#}=39.7 \mathrm{kcal} \mathrm{mol}^{-1}$. This elevated activation barrier is consistent with a recent study by Mindiola, Baik and coworkers. They computed the cleavage of an $\eta^{2}$-N,C-quinolyl unit [bonded as titanaaziridine moiety] with subsequent nucleophilic attack on a quinoline molecule at similar elevated energies of 27.9 to $40.1 \mathrm{kcal} \mathrm{mol}^{-1}$ (depending on the substrate and spin state). ${ }^{47}$ In light of our results and the congruence with previous findings, it was concluded that the reductive coupling reaction of pyridine unlikely proceeds along this reaction pathway.

Hence, the focus was shifted towards an initial C-C coupling step of two pyridine molecules. Two reaction sequences are possible: the two pyridine moieties could undergo C-C coupling with the hydrogen atoms in the 2-positions pointing to (i) the same (syn) or (ii) to the opposite (anti) direction of the formed bipyridine plane. The latter was eliminated as $\mathrm{H}_{2}$ elimination from the anti-coupled intermediate, Anti-3, appeared unlikely (cf. Chart 3).$^{\mathbf{8 3}}$ Even though the first $\mathrm{C}-\mathrm{H}$ activation to transfer one hydrogen atom onto $\mathrm{Zr}$ is easy $\left(\Delta G^{\ddagger}=5.6\right.$ and $\Delta G=$ $-10.8 \mathrm{kcal} \mathrm{mol}^{-1}$ ), forming Anti-4, the subsequent H-transfer to form $\mathrm{H}_{2}$ is associated with a high lying TS (Anti-4-TS). In addition, the TS for rotation around the central $\mathrm{C}-\mathrm{C}$ bond to reach, from Anti-4, a geometry more suited to $\mathrm{C}-\mathrm{H}$ bond cleavage in Anti-4-TS could not be found. Therefore, the energy difference between Anti-4-TS and Anti-4, $\Delta G^{\ddagger}=37.3 \mathrm{kcal} \mathrm{mol}^{-1}$, is a lower limit of the actual activation barrier. This is too high a value to be representative of the situation observed experimentally.

Therefore, attention was focused on the syn C-C coupling reaction sequence (Fig. 5, black). After the almost thermoneutral substitution of toluene by pyridine and the concomitant formation of a low-valent $\mathrm{Zr}^{\mathrm{II}}$ species, the coordination of a second pyridine molecule generates the precursor of the $\mathrm{C}-\mathrm{C}$ coupling process, Syn-1, at $\Delta G=17.7 \mathrm{kcal} \mathrm{mol}^{-1}$ with respect to the starting reactants. The exergonic formation of the $\mathrm{C}-\mathrm{C}$ bond leading to Syn-2 ( $\Delta G=-21.7 \mathrm{kcal} \mathrm{mol}^{-1}$ from Syn-1) is effective through Syn-1-TS with $\Delta G^{*}=8.7 \mathrm{kcal} \mathrm{mol}^{-1}$ (Fig. 6) and transforms the $\mathrm{Zr}^{\mathrm{II}}$ species, Syn-1, into the $\mathrm{Zr}^{\mathrm{IV}}$ species, Syn-2. Considering this, two spin states are possible: Syn-1 or Syn-1T

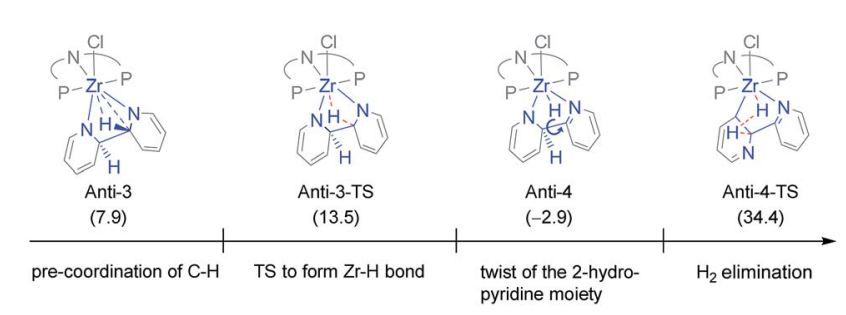

Chart 3 Visualization of the disfavoured $\mathrm{H}_{2}$ elimination in the case of the anti $\mathrm{C}-\mathrm{C}$ coupling sequence. Values in parentheses are calculated free energies in $\mathrm{kcal} \mathrm{mol}^{-1}$ in reference to $\eta^{6}$-arene complex 1 (Anti-4TS: due to the twist around the py-py axis, the negative charge is located at the $\mathrm{C} 6$ carbon atom, which coordinates to the zirconium metal centre).

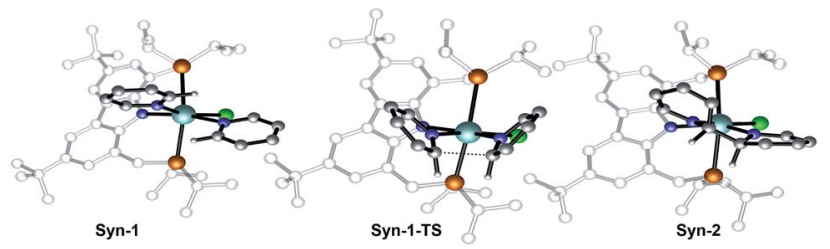

Fig. 6 Optimized geometries of the extrema located along the reaction pathway for the $\mathrm{C}-\mathrm{C}$ bond formation.

and Syn-1-TS (singlet or triplet). A geometry for Syn-1 in the triplet state, Syn-1T, could be located on the potential energy surface at $\Delta G=9.1 \mathrm{kcal} \mathrm{mol}^{-1}$ with respect to 1 . Fig. 7 shows the spin density for Syn-1T and clearly highlights significant accumulation of spin density on both the ortho and para carbon atoms of the coordinated pyridine ligands. This electronic pattern is computed to be more stable than the singlet state Syn$\mathbf{1}$ and supports electron transfer from $\mathrm{Zr}$ to the coordinated pyridine before the actual $\mathrm{C}-\mathrm{C}$ coupling step. However, attempts to locate a triplet transition state similar to Syn-1-TS failed as the same spin density on the ortho carbon atoms would prevent formation of the $\mathrm{C}-\mathrm{C}$ bond, indicating the limitations of the computational strategy adopted in this paper. Subsequent isomerization to Syn-3 to position the $\mathrm{C}-\mathrm{H}$ bond close to $\mathrm{Zr}$ is endergonic $\left(\Delta G=10.9 \mathrm{kcal} \mathrm{mol}^{-1}\right)$ but leads to an easy C-H bond cleavage through Syn-3-TS $\left(\Delta G^{\ddagger}=4.8 \mathrm{kcal} \mathrm{mol}^{-1}\right.$, Fig. 8). The product of this $\mathrm{C}-\mathrm{H}$ activation, Syn-4, lies at the same energy as the product of C-C syn coupling Syn-2.

The second $\mathrm{C}-\mathrm{H}$ bond cleavage is achieved through Syn-4-TS, in a $\sigma$-bond metathesis with $\Delta G^{\ddagger}=13 \mathrm{kcal} \mathrm{mol}^{-1}$ (Fig. 9). The last transformation is strongly exergonic and forms the product 3-H. Overall the energy barrier to overcome in order to form 3-H along the reaction pathway depicted in black in Fig. 5 is $26.4 \mathrm{kcal} \mathrm{mol}^{-1}$, associated with the TS for the $\mathrm{C}-\mathrm{C}$ bond formation between two coordinated pyridine ligands.

Such a value is in very good agreement with the observed experimental conditions in terms of reaction time and

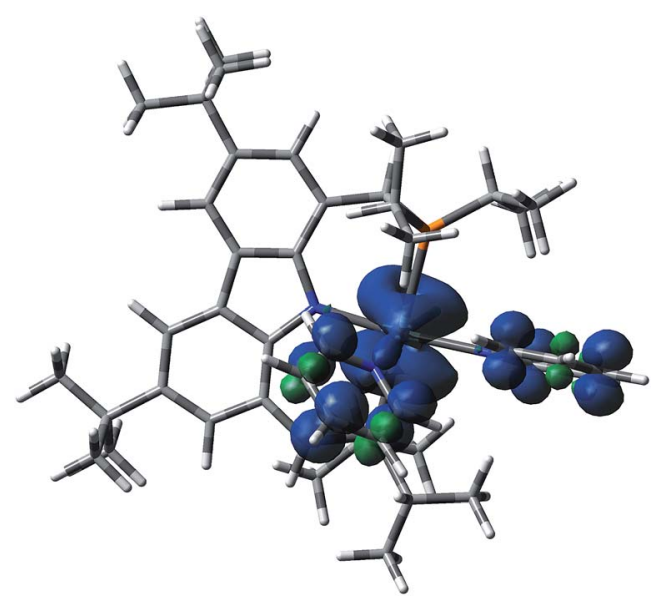

Fig. 7 Visualization of the spin density in Syn-1T, showing the spin density in the ortho and para carbon atoms of the coordinated pyridines 


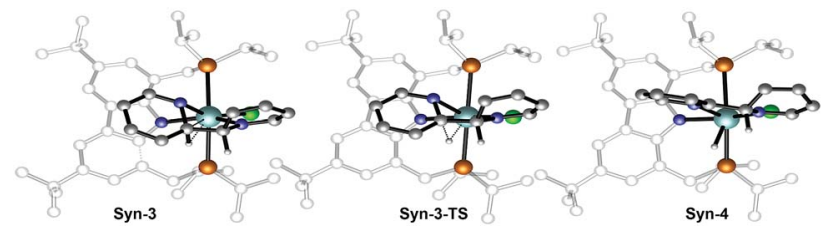

Fig. 8 Optimized geometries of the extrema located along the reaction pathway for the hydrogen transfer from the $\mathrm{C}-\mathrm{C}$ coupled $2 H, 2^{\prime} H-\left[2,2^{\prime}\right.$-bipyridine]-1, $1^{\prime}$-diide ligand to the zirconium central atom.

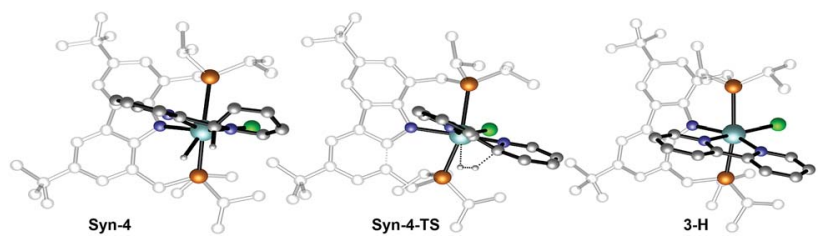

Fig. 9 Optimized geometries of the extrema located along the reaction pathway for the hydrogen elimination from Syn-4 to form bipyridyl complex 3-H.

temperature. To further probe the validity of this mechanism, the theoretical kinetic isotope effect (KIE) of the rate determining step for the Syn and the $\mathbf{C H}$ reaction sequences was modelled through normal coordinate analysis of the DFT reactant and the transition state structures (reactant (Syn1/CH-3) $\rightarrow$ ts (Syn-1-TS/CH-3-TS)) by the Bigeleisen-Mayer approach..$^{84-86}$ This resulted in the KIE(Syn-1-TS $)_{\text {theor }}=1.32$ for the transformation from Syn-1 to Syn-2, whereas a value of $\mathrm{KIE}(\mathbf{C H}-3-\mathrm{TS})_{\text {theor }}=0.92$ was found for the conversion of $\mathbf{C H}-\mathbf{3}$ to CH-4. The experimental KIE was evaluated through the reaction of ${ }^{\mathrm{Cbz}}(\mathrm{PNP}) \mathrm{ZrCl}\left(\eta^{6}\right.$-arene) complex 1 with an excess of both, pyridine and pyridine- $\mathrm{d}_{5}$, and determined to be $\mathrm{KIE}_{\exp }=$ 1.29. The experimental value agrees well with $\mathrm{KIE}(\mathbf{S y n}-\mathbf{1}-\mathbf{T S})_{\text {theor }}$ and further corroborates that the dehydrogenative coupling of 4 -substituted pyridines proceeds along the suggested syn C-C coupling sequence ( $c f$. Fig. 5 - black).

\section{DFT modelling of the competitive reaction paths for 2- picoline, DMAP and isoquinoline}

Based on deuteration experiments as well as DFT calculations, the reaction mechanisms involving a cyclometallated ligand backbone or an anti-arranged C-C coupling step were precluded as viable reaction pathways for the reductive coupling of pyridine and a variety of its 4-substituted analogues. Nevertheless, it was observed that selected substrates were converted into intermediates of the two aforementioned reaction pathways ( $c f$. Schemes 3 and 4). To get more insight into these experimental observations, the computations for the crucial transition states found for the reductive coupling of pyridine were repeated with the respective substrate molecules, namely 2-picoline, DMAP and isoquinoline.

For 2-picoline and DMAP, the initial syn $\mathrm{C}-\mathrm{C}$ coupling transition states were modelled. The calculated activation barriers were significantly higher for 2-picoline $\left(\Delta G^{\ddagger}=15.3 \mathrm{kcal} \mathrm{mol}^{-1}\right)$ and DMAP $\left(\Delta G^{\dagger}=22.3 \mathrm{kcal} \mathrm{mol}^{-1}\right)$ than the value obtained for pyridine $\left(\Delta G^{\ddagger}=8.7 \mathrm{kcal} \mathrm{mol}^{-1}\right)$. As a consequence, the corresponding TS ( ${ }^{\mathbf{M e}}$ Syn-1-TS and ${ }^{\text {DMAP }}$ Syn-1-TS) lie at too high free energies with respect to the separated reactants to provide reactive pathways (Fig. 10).

In the case of pyridine, the reaction pathway involving a cyclometallated ligand was excluded based on the deuterium labelling experiments. Nevertheless, the transition state Cy-1-TS corresponding to the extrusion of $\mathrm{H}_{2}$ from $\mathbf{C H}-2$ leading to the cyclometallated $\eta^{2}$-pyridyl complex $\mathbf{C y - 2}$ was computed to lie at $\Delta G=23.3 \mathrm{kcal} \mathrm{mol}^{-1}$ with respect to the separated reactants (Fig. 10). The computed Gibbs free energies for Syn-1-TS (26.4 kcal mol ${ }^{-1}$ ) and Cy-1-TS $\left(23.3 \mathrm{kcal} \mathrm{mol}^{-1}\right)$ support preferred formation of Cy-2 with respect to Syn-2, both lying at the same energy $\left(\Delta G=-4.0 \mathrm{kcal} \mathrm{mol}^{-1}\right)$. However, the values of the Gibbs free energies for the two competing transition states are rather to one another.

Interestingly, the difference in energy between these two crucial transition states deciding the final outcome of the reaction is strongly influenced by the nature of the substituent on the pyridine. With 2-picoline and DMAP, the transition states, ${ }^{\mathbf{M e}} \mathbf{C y - 1 - T S}$ and ${ }^{\text {DMAP }} \mathbf{C y - 1 - T S}$, leading to the cyclometallated $\eta^{2}$-pyridyl complex, ${ }^{\mathbf{M e}} \mathbf{C y}-\mathbf{2}$ and ${ }^{\mathbf{D M A P}} \mathbf{C y - 2}$, lie at lower energy (22.0 and $20.8 \mathrm{kcal} \mathrm{mol}^{-1}$, respectively) compared to the unsubstituted case (Fig. 10). With the substituted pyridine rings there is thus a clear preference for the pathway leading to the cyclometallated $\eta^{2}$-pyridyl complex in perfect agreement with the experimental observations. This situation is the result of both a more energy-demanding $\mathrm{C}-\mathrm{C}$ coupling for the substituted heterocycles and an easier $\mathrm{H}_{2}$ extrusion upon cyclometallation.

With 2-picoline and DMAP, the cyclometallated $\eta^{2}$-pyridyl complexes are dead-ends as further reaction with another equivalent of substituted pyridine is associated with high lying transition states. The activation barrier for $\mathrm{C}-\mathrm{C}$ coupling from ${ }^{\mathrm{Me}} \mathbf{C y}-2$ and ${ }^{\text {DMAP }} \mathbf{C y}-2$, through ${ }^{\mathbf{M e}} \mathbf{C y}-3$-TS and ${ }^{\text {DMAP }} \mathbf{C y}-3-\mathbf{T S}$, are $\Delta G^{\#}=40.6 \mathrm{kcal} \mathrm{mol}^{-1}$ and $\Delta G^{\#}=34.3 \mathrm{kcal} \mathrm{mol}^{-1}$, respectively. The reactivity of 2-picoline can be traced back to a steric repulsion of the methyl substituents with the isopropyl groups of the ligand destabilizing ${ }^{\mathbf{M e}}$ Syn-1-TS. In contrast, the reactivity of DMAP is electronically induced due to a more facile activation of $\mathrm{C}-\mathrm{H}$ bonds of electron rich arenes. ${ }^{12}$ Furthermore, other 4-substituted pyridines with sterically more demanding substituents were readily transformed to $\mathbf{3 - R}$, ruling out steric effects of the $\mathrm{NMe}_{2}$ substituent in DMAP.

Further attention was given to the competitive reaction path resulting in the anti $\mathrm{C}-\mathrm{C}$ coupling of isoquinoline to form complex 5. For this purpose, the previously described syn- and anti-coupling steps were modelled with isoquinoline as the substrate and compared to the ones computed for pyridine. However, despite numerous attempts no transition state leading to complex 5, such as ${ }^{\mathbf{I q}}$ Anti-1-TS depicted in Fig. 11, could be located. A scan of the potential energy surface along the $\mathrm{C}-\mathrm{C}$ distance between the $\mathrm{C} 1$ and $\mathrm{C}^{\prime}$ isoquinoline carbon atoms only showed shallow maxima ( $c f$. ESI $\dagger)$. In this context, a comparison of the energies of the transition states obtained for the competition between syn and anti-CC couplings for 


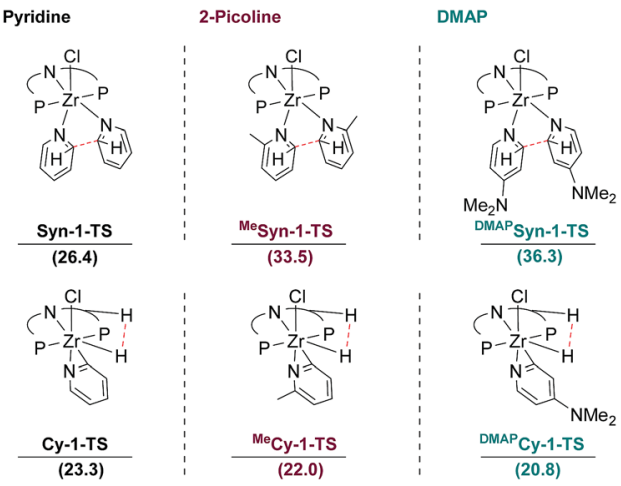

Fig. 10 Comparison of the Gibbs free energies ( $\mathrm{kcal} \mathrm{mol}^{-1}$ ) of the TS for syn $\mathrm{C}-\mathrm{C}$ coupling and $\mathrm{H}_{2}$ extrusion to form cyclometallated $\eta^{2}$ pyridyl complexes: left for pyridine, middle for 2-picoline and right for DMAP.

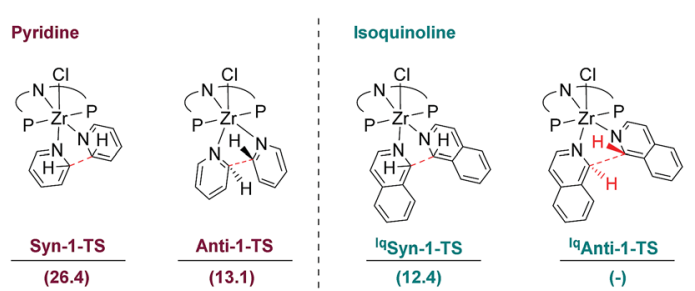

Fig. 11 Gibbs free energies ( $\mathrm{kcal}^{\mathrm{mol}}{ }^{-1}$ ), relative to the separated reactants, for the syn- and anti-transition state for pyridine as well as isoquinoline.

pyridine and the value obtained for syn-CC coupling for isoquinoline are instructive (Fig. 11). Notably, the anti-coupling step for pyridine (Anti-1-TS) is $13.3 \mathrm{kcal} \mathrm{mol}^{-1}$ lower in energy than the corresponding syn-transformation (Syn-1-TS). With isoquinoline as the substrate, the Gibbs free energy for the syncoupling transition state ( $\left.{ }^{\mathrm{Iq}} \mathbf{S y n}-\mathbf{1 - T S}\right)$ was calculated to be $14 \mathrm{kcal} \mathrm{mol}^{-1}$ lower than that obtained for the pyridine transition state. Consequentially, if a similar energy lowering is applied to ${ }^{\mathbf{I q}} \mathbf{A n t i - 1 - T S}$, then the anti-CC coupling for isoquinoline should be associated with a very low activation barrier if any. Moreover, the resulting anti-CC coupling step is associated with a very exergonic transformation with $\Delta G=$ $-19.7 \mathrm{kcal} \mathrm{mol}^{-1}$. It can be concluded that, in the case of isoquinoline, an anti-coupling is favoured over a syn-coupling, thus explaining the reactivity observed experimentally.

\section{Conclusions}

We investigated the reductive coupling of pyridine mediated by the $\mathrm{Zr}^{\mathrm{II}}$ synthon, ${ }^{\mathrm{Cbz}}(\mathrm{PNP}) \mathrm{ZrCl}\left(\eta^{6}\right.$-toluene $)$ 1. In this context, we were able to gain insights into the range of possible substrates and expanded the substrate scope for this reaction. Through experimental and extensive computational investigations, we were able to rule out several possible reaction paths and put forward a reaction mechanism which has been disregarded in previous publications concerning pyridine homocoupling reactions. To our knowledge, we report the first reductive coupling of pyridine proceeding via an initial syn C-C coupling step, instead of an initial $\mathrm{C}-\mathrm{H}$ activation of the pyridine substrate. Further DFT calculations provided explanations for the observed deviation from the main reaction path in case of the substrates 2-picoline, DMAP and isoquinoline.

\section{Conflicts of interest}

There are no conflicts to declare.

\section{Acknowledgements}

The authors thank the University of Heidelberg and the Deutsche Forschungsgemeinschaft (SFB 1249) for funding this work and acknowledge support by the state of Baden-Württemberg through bwHPC.

\section{Notes and references}

1 I. P. Rothwell, Polyhedron, 1985, 4, 177-200.

2 P. J. Chirik, Organometallics, 2010, 29, 1500-1517.

3 H. Brintzinger and J. E. Bercaw, J. Am. Chem. Soc., 1971, 93, 2045-2046.

$4 \mathrm{~W}$. A. Nugent, D. W. Ovenall and S. J. Holmes, Organometallics, 1983, 2, 161-162.

5 H. Brunner, G. Gehart, W. Meier, J. Wachter, A. Riedel, S. Elkrami, Y. Mugnier and B. Nuber, Organometallics, 1994, 13, 134-140.

6 A. Bertuleit, C. Fritze, G. Erker and R. Fröhlich, Organometallics, 1997, 16, 2891-2899.

7 J. Pflug, A. Bertuleit, G. Kehr, R. Fröhlich and G. Erker, Organometallics, 1999, 18, 3818-3826.

8 B. C. Bailey, H. Fan, J. C. Huffman, M.-H. Baik and D. J. Mindiola, J. Am. Chem. Soc., 2007, 129, 8781-8793.

9 M. Manßen, N. Lauterbach, J. Dörfler, M. Schmidtmann, W. Saak, S. Doye and R. Beckhaus, Angew. Chem., Int. Ed., 2015, 54, 4383-4387.

10 M. E. Thompson and J. E. Bercaw, Pure Appl. Chem., 1984, 56, 1-11.

11 I. P. Rothwell, Acc. Chem. Res., 1988, 21, 153-159.

12 M. E. Thompson, S. M. Baxter, A. R. Bulls, B. J. Burger, M. C. Nolan, B. D. Santarsiero, W. P. Schaefer and J. E. Bercaw, J. Am. Chem. Soc., 1987, 109, 203-219.

13 G. Erker, J. Organomet. Chem., 1977, 134, 189-202.

14 C. C. Cummins, S. M. Baxter and P. T. Wolczanski, J. Am. Chem. Soc., 1988, 110, 8731-8733.

15 C. P. Schaller, C. C. Cummins and P. T. Wolczanski, J. Am. Chem. Soc., 1996, 118, 591-611.

16 A. E. Shilov, Activation of Saturated Hydrocarbons by Transition Metal Complexes, D. Reidel, 1984.

17 S. Murai, Activation of Unreactive Bonds and Organic Synthesis, Springer-Verlag, 1999.

18 J. Halpern, Inorg. Chim. Acta, 1985, 100, 41-48.

19 G. W. Parshall, Acc. Chem. Res., 1970, 3, 139-144.

20 R. H. Crabtree, J. Organomet. Chem., 2004, 689, 4083-4091.

21 A. E. Shilov and A. A. Shteinman, Coord. Chem. Rev., 1977, 24, 97-143. 
22 D. E. Webster, in Advances in Organometallic Chemistry, ed. R. W. F.G.A. Stone, Academic Press, 1977, vol. 15, pp. 147188.

23 G. W. Parshall, Acc. Chem. Res., 1975, 8, 113-117.

24 D. A. Colby, R. G. Bergman and J. A. Ellman, Chem. Rev., 2010, 110, 624-655.

25 D. Balcells, E. Clot and O. Eisenstein, Chem. Rev., 2010, 110, 749-823.

26 M. I. Bruce, Angew. Chem., Int. Ed., 1977, 16, 73-86.

27 I. Omae, Coord. Chem. Rev., 1979, 28, 97-115.

28 I. Omae, Chem. Rev., 1979, 79, 287-321.

29 R. H. Crabtree, Chem. Rev., 1985, 85, 245-269.

30 M. Albrecht, Chem. Rev., 2010, 110, 576-623.

31 I. Omae, Cyclometalation Reactions, Springer Japan, Tokyo, 2014.

32 J. Dehand and M. Pfeffer, Coord. Chem. Rev., 1976, 18, 327352.

33 E. C. Constable, Polyhedron, 1984, 3, 1037-1057.

34 I. Omae, Coord. Chem. Rev., 1988, 83, 137-167.

35 C. A. Bradley, E. Lobkovsky and P. J. Chirik, J. Am. Chem. Soc., 2003, 125, 8110-8111.

36 D. P. Krut'ko, R. S. Kirsanov, S. A. Belov, M. V Borzov, A. V Churakov and J. A. K. Howard, Polyhedron, 2007, 26, 28642870.

37 R. F. Jordan and D. F. Taylor, J. Am. Chem. Soc., 1989, 111, 778-779.

38 R. F. Jordan, D. F. Taylor and N. C. Baenziger, Organometallics, 1990, 9, 1546-1557.

39 R. F. Jordan and A. S. Guram, Organometallics, 1990, 9, 21162123.

40 S. Kuppuswamy, I. Ghiviriga, K. A. Abboud and A. S. Veige, Organometallics, 2010, 29, 6711-6722.

41 M. Oishi, T. Kato, M. Nakagawa and H. Suzuki, Organometallics, 2008, 27, 6046-6049.

42 M. Oishi, M. Oshima and H. Suzuki, Inorg. Chem., 2014, 53, 6634-6654.

43 T. Kurogi, M. E. Miehlich, D. Halter and D. J. Mindiola, Organometallics, 2018, 37, 165-167.

44 S. Ren and Z. Xie, Organometallics, 2011, 30, 5953-5959.

45 G. P. McGovern, F. Hung-Low, J. W. Tye and C. A. Bradley, Organometallics, 2012, 31, 3865-3879.

46 I. M. Piglosiewicz, S. Kraft, R. Beckhaus, D. Haase and W. Saak, Eur. J. Inorg. Chem., 2005, 938-945.

47 S. Baek, T. Kurogi, D. Kang, M. Kamitani, S. Kwon, D. P. Solowey, C.-H. Chen, M. Pink, P. J. Carroll, D. J. Mindiola and M.-H. Baik, J. Am. Chem. Soc., 2017, 139, 12804-12814.

48 G. R. Newkome, A. K. Patri, E. Holder and U. S. Schubert, Eur. J. Org. Chem., 2004, 235-254.

49 G. Chelucci and R. P. Thummel, Chem. Rev., 2002, 102, 31293170.

50 L. A. Summers, in Advances in Heterocyclic Chemistry, ed. A.

R. Katritzky, Academic Press, 1984, pp. 281-374.

51 F. Kröhnke, Synthesis, 1976, 1-24.

52 R. Chinchilla, C. Nájera and M. Yus, Chem. Rev., 2004, 104, 2667-2722.

53 G. M. Badger and W. H. F. Sasse, J. Chem. Soc., 1956, 616.
54 W. H. F. Sasse and C. P. Whittle, J. Chem. Soc., 1961, 13471350.

55 P. E. Rosevear and W. H. F. Sasse, J. Heterocycl. Chem., 1971, 8, 483-485.

56 H. Hagelin, B. Hedman, I. Orabona, T. Åkermark, B. Åkermark and C. A. Klug, J. Mol. Catal. A: Chem., 2000, 164, 137-146.

57 T. Kawashima, T. Takao and H. Suzuki, J. Am. Chem. Soc., 2007, 129, 11006-11007.

58 T. Takao, T. Kawashima, H. Kanda, R. Okamura and H. Suzuki, Organometallics, 2012, 31, 4817-4831.

59 M. Nagaoka, T. Kawashima, H. Suzuki and T. Takao, Organometallics, 2016, 35, 2348-2360.

60 B. R. Cockerton and A. J. Deeming, J. Organomet. Chem., 1992, 426, 92-95.

$61 \mathrm{H}$. Sen Soo, P. L. Diaconescu and C. C. Cummins, Organometallics, 2004, 23, 498-503.

62 M. E. Viguri, J. Pérez and L. Riera, Chem.-Eur. J., 2014, 20, 5732-5740.

63 Y. Shibata, H. Nagae, S. Sumiya, R. Rochat, H. Tsurugi and K. Mashima, Chem. Sci., 2015, 6, 5394-5399.

64 R. J. P. Corriu, C. Guerin, B. Henner and Q. Wang, Organometallics, 1991, 10, 2297-2303.

65 J. R. Hagadorn and J. Arnold, Angew. Chem., 1998, 110, 18131815.

66 O. V. Ozerov, B. O. Patrick and F. T. Ladipo, J. Am. Chem. Soc., 2000, 122, 6423-6431.

67 D. Kissounko, A. Epshteyn, J. C. Fettinger and L. R. Sita, Organometallics, 2006, 25, 531-535.

68 W. A. Chomitz, A. D. Sutton, J. L. Krinsky and J. Arnold, Organometallics, 2009, 28, 3338-3349.

69 G. T. Plundrich, H. Wadepohl, E. Clot and L. H. Gade, Chem.-Eur. J., 2016, 22, 9283-9292.

70 G. T. Plundrich, H. Wadepohl and L. H. Gade, Inorg. Chem., 2016, 55, 353-365.

71 V. B. R. S. I. Troyanov and G. N. Mazo, Zh. Neorg. Khim., 1988, 33, 2798-2801.

72 E. König and S. Kremer, Chem. Phys. Lett., 1970, 5, 87-90.

73 A. C. Bowman, J. England, S. Sproules, T. Weyhermüller and K. Wieghardt, Inorg. Chem., 2013, 52, 2242-2256.

74 A. K. Hickey, M. G. Crestani, A. R. Fout, X. Gao, C.-H. Chen and D. J. Mindiola, Dalton Trans., 2014, 43, 9834-9837.

75 D. Chen, G. Xu, Q. Zhou, L. W. Chung and W. Tang, J. Am. Chem. Soc., 2017, 139, 9767-9770.

76 J. E. Bercaw, P. T. Wolczanski and D. L. Davies, Organometallics, 1986, 5, 443-450.

77 L. Becker, P. Arndt, H. Jiao, A. Spannenberg and U. Rosenthal, Angew. Chem., Int. Ed., 2013, 52, 1139611400.

78 L. Becker, V. V. Burlakov, P. Arndt, A. Spannenberg, W. Baumann, H. Jiao and U. Rosenthal, Chem.-Eur. J., 2013, 19, 4230-4237.

79 L. Becker, F. Strehler, M. Korb, P. Arndt, A. Spannenberg, W. Baumann, H. Lang and U. Rosenthal, Chem.-Eur. J., 2014, 20, 3061-3068.

80 L. Becker, P. Arndt, A. Spannenberg, H. Jiao and U. Rosenthal, Angew. Chem., Int. Ed., 2015, 54, 5523-5526. 
81 K. Altenburger, P. Arndt, L. Becker, F. Reiß, V. V. Burlakov, A. Spannenberg, W. Baumann and U. Rosenthal, Chem.Eur. J., 2016, 22, 9169-9180.

82 M. J. Frisch, G. W. Trucks, H. B. Schlegel, G. E. Scuseria, M. A. Robb, J. R. Cheeseman, G. Scalmani, V. Barone, B. Mennucci, G. A. Petersson, H. Nakatsuji, M. Caricato, X. Li, H. P. Hratchian, A. F. Izmaylov, J. Bloino, G. Zheng, J. L. Sonnenberg, M. Hada, M. Ehara, K. Toyota, R. Fukuda, J. Hasegawa, M. Ishida, T. Nakajima, Y. Honda, O. Kitao, H. Nakai, T. Vreven, J. A. Montgomery Jr, J. E. Peralta, F. Ogliaro, M. Bearpark, J. J. Heyd, E. Brothers, K. N. Kudin, V. N. Staroverov, T. Keith, R. Kobayashi, J. Normand, K. Raghavachari, A. Rendell, J. C. Burant, S. S. Iyengar, J. Tomasi, M. Cossi, N. Rega, J. M. Millam, M. Klene, J. E. Knox, J. B. Cross, V. Bakken, C. Adamo, J. Jaramillo, R. Gomperts, R. E. Stratmann, O. Yazyev, A. J. Austin, R. Cammi, C. Pomelli,
J. W. Ochterski, R. L. Martin, K. Morokuma, V. G. Zakrzewski, G. A. Voth, P. Salvador, J. J. Dannenberg, S. Dapprich, A. D. Daniels, O. Farkas, J. B. Foresman, J. V. Ortiz, J. Cioslowski, and D. J. Fox, Gaussian, Inc., Gaussian 09, Revision D.01, Wallingford CT, 2013.

83 The bis-coordinated pyridine complex prior to anti-CC coupling, Anti-1, is computed at $\Delta \mathrm{G}=6.0 \mathrm{kcal}$ mol-1. The C-C coupling through Anti-1-TS has an activation barrier of $\Delta \mathrm{G} \#=7.1 \mathrm{kcal}$ mol-1 and the reaction is exoergic with Anti-2 lying at $\Delta G=-8.8 \mathrm{kcal}$ mol-1 with respect to the reactants.

84 J. Bigeleisen, J. Chem. Phys., 1949, 17, 675-678.

85 M. Wolfsberg, Acc. Chem. Res., 1972, 5, 225-233.

86 The program diagonalizes the mass-weighted Hessian matricies to obtain harmonic vibrational frequencies and Bigeleisen-Mayer Reduced Isotopic Partition Function Ratios. 